\title{
Effects of maquis clearing on the properties of the soil and on the near-surface hydrological processes in a semi-arid Mediterranean environment
}

\author{
Mario Pirastru, Marcello Niedda, Mirko Castellini \\ Agricultural Department, University of Sassari, Italy
}

\begin{abstract}
Many hillslopes covered with maquis in the semi-arid Mediterranean environment have been cleared in recent decades. There is little information on what effect this has on the hydrology of the soil. We compared the hydraulic properties of the soil and the subsurface hydrological dynamics on two adjacent sites on a hillslope. One site was covered with maquis, the other with grass. The grass started to grow some 10 years ago, after the maquis had been cleared and the soil had been ploughed. Our study found that the hydraulic properties and the hydrological dynamics of the maquis and the grassed soil differed greatly. The grassed soil had less organic matter and higher apparent density than did the soil covered in maquis. Moreover, the maquis soil retained more water than the grassed soil in the tension range from saturation to $50 \mathrm{~cm}$ of water. Infiltration tests performed in summer and in winter indicated that the field saturated hydraulic conductivity $\left(\mathrm{K}_{\mathrm{fs}}\right)$ of the maquis soil was higher than that of the grassy soil. However the data showed that the $\mathrm{K}_{\mathrm{fs}}$ of the two soils changed with the season. In the maquis soil the $\mathrm{K}_{\mathrm{fs}}$ increased from summer to winter. This was assumed to be due to water flowing more efficiently through wet soil. By contrast, in the grassy soil the $\mathrm{K}_{\mathrm{fs}}$ decreased from summer to winter. This was because the desiccation cracks closed in the wet soil. As result, the influence of the land use change was clear from the $\mathrm{K}_{\mathrm{fs}}$ measurements in winter, but less so from those in the summer. Changes in land use altered the dynamics of the infiltration, subsurface drainage and soil water storage of the soil. The maquis soil profile never satu-
\end{abstract}

Correspondence: Mario Pirastru, Agricultural Department, University of Sassari, viale Italia 39,07100 Sassari, Italy.

Tel.: +39.079 .229342 - Fax: +39.079 .229340$

E-mail: mpirastru@uniss.it

Key words: Mediterranean maquis clearing, land use, hydraulic properties, field monitoring, soil water, water table.

Received for publication: 22 July 2014.

Accepted for publication: 23 November 2014.

(c) Copyright M. Pirastru et al., 2014

Licensee PAGEPress, Italy

Journal of Agricultural Engineering 2014; XLV:428

doi:10.4081/jae.2014.428

This article is distributed under the terms of the Creative Commons Attribution Noncommercial License (by-nc 3.0) which permits any noncommercial use, distribution, and reproduction in any medium, provided the original author(s) and source are credited. rated completely, and only short-lived, event based perched water tables were observed. By contrast, soil saturation and a shallow water table were observed in the grass covered site throughout the wet season. The differences were assumed to be due to the high canopy interception of the maquis cover, and to the macropores in the grassed soil being destroyed after the maquis had been cleared and the soil ploughed.

The results of this work are helpful for predicting the changes in the hydraulic properties of the soil and in the near-surface hydrological processes in similar Mediterranean environments where the natural vegetation has been cleared. These changes must be taken into consideration when developing rainfall-runoff models for flood forecasting and water yield evaluation.

\section{Introduction}

The hydrological properties of the soil depend greatly on the vegetation type and soil management. Land-use controls the hydrological processes in the soil at plot, hillslope and basin scale. In an attempt to explain the impact of the land use in the soil hydrology, and thus define a policy for sustainable land use management, hydrologists have investigated the influence of land use on the hydraulic properties of the soil. Many authors (e.g. Gajić, 2013; Martinez and Zinck, 2004; Gonzales-Sosa et al., 2010; Price et al., 2010; Iovino et al., 2013) have reported that deforested soils have lower organic matter content and higher bulk density than do forested soils. The water retention characteristics and the hydraulic conductivity of soil also were different between land uses. This was particularly evident in the topsoil and in the water content at saturation (Gajić, 2013; De Moraes et al., 2006; Zimmermann et al., 2006; Alaoui et al., 2011). However, Evrendilek et al. (2004) reported that bulk densities did not vary between forest and pasture in the Mediterranean highlands of Turkey. Agnese et al. (2011) also reported that, for two of the five sites investigated in a Mediterranean watershed, bulk density did not differ for forest and the pasture areas. Sauer and Logsdon (2002), Hassler et al. (2010) and Celik (2005) also found that saturated hydraulic conductivity measured in field did not differ for forest and grassland. These contrasting results in the literature are due to the fact that the effects of land use vary greatly, depending on the climate, morphology, vegetation, soil types and land management practices. Hence the differences in the hydrological properties of the soil in areas with different land use cannot be assumed $a$ priori, and need to be verified for each of the different types of environment.

Although the effects of the land use on the hydraulic properties of the soil have been studied intensively in recent decades, less attention has been paid to investigating the related impact in the nearsurface soil hydrological processes, such as the dynamics of soil moisture and the water table. 
For example, Gallart et al. (1997) studied the variations in soil water storage over time in a Mediterranean mountain basin in the Pyrenees. They observed that the soil profiles in forested areas always had lower water content than did those in cleared areas. This was mainly attributed to the forest interception, which can be even higher than the potential evapotranspiration. In their study they found that forest cover played an equally important role in determining the spatial distribution of the soil water reserves as did the topographic situation. Fu et al. (2003) investigated the soil moisture patterns of seven vegetation types in the semiarid area of the Loess Plateau of China. They found that intercrop (bare) soils had higher water content than soil covered in vegetation, and that grass covered soil had higher soil moisture content than forested soil. They asserted that the main reasons for this were the interception of the trees and the differences in the physical properties of the soil. These affected the infiltration rate, storage and redistribution of soil water in the investigated land uses. Mollnau et al. (2014) studied the soil water dynamics under a western juniper (Juniperus occidentalis) woodland and compared their results with those for a site where the woods had been cut down. They found that the soil moisture content was higher in sites where the tree cover had been cleared. The woodland had a negative impact on deep water reserve recharge. This was due to the high interception rate of the juniper, and also its ability to extract water from deep soil strata.

Little information is available in semi-arid Mediterranean watersheds on the effects that clearing natural vegetation has on the hydraulic properties of the soil and its hydrological processes. Understanding how the soil responds after land use change is essential for researchers and planners that work in this semiarid environment, so that they can develop strategies for conserving the water and the soil and minimising flood risks. In this type of climate, the high frequency of intense rainfall events and the seasonal mismatch between evapotranspiration and rainfall results in more intense storm-flow and erosion in the watersheds (Piňol et al., 1997; Costa et al., 2003; Cantón et al., 2011). The main aim of this work is to investigate the effects of clearing Mediterranean maquis on the hydrology of the soil, in an area which already suffers from land use degradation. The soil on a hillslope with two different types of land use, i.e. a well developed mediterranean maquis and an area covered with spontaneous grass, was analysed hydrologically. The specific objectives were to investigate how the removal of the mediterranean maquis influenced: i) the hydrological properties of the soil; ii) the near-surface water flow processes.

First, the results of measuring soil properties (texture, organic matter and bulk density), water retention and hydraulic conductivity are presented, and the difference between the land use classes analysed. Second, the observed dynamics of soil moisture and of the perched water table in the soil under the grass and the maquis are described. This information is then used to develop hypotheses about how clearing the maquis changes the infiltration, drainage and storage mechanisms in the soil.

\section{Materials and methods}

\section{Site description}

The experimental area is located in the Baratz Lake watershed (Niedda and Pirastru, 2013; Pirastru and Niedda, 2013), in north-west Sardinia, Italy. Baratz Lake is the only natural lake in Sardinia, and contributes significantly to the maintenance of biological diversity. It was declared a site of community importance in the NATURA 2000 network, as defined by the European Commission Habitats Directive (92/43/EEC) (http://ec.europa.eu/environment/nature/natura2000/). Baratz Lake has suffered from hydrological and ecological degradation in recent years. This is due to a decrease in precipitation and the conversion of some parts of the basin from Mediterranean shrubland (maquis) and woods to pasture and arable lands (Niedda et al., 2014). The climate is semi-arid Mediterranean, with a mild winter, a warm summer, and a high water deficit between April and September. Mean annual temperature is $15.8^{\circ} \mathrm{C}$ and relative humidity $78.7 \%$. Minimum and maximum mean daily temperatures are $3^{\circ} \mathrm{C}$ and $29^{\circ} \mathrm{C}$, respectively. Average annual precipitation is about $600 \mathrm{~mm}$, and this falls mainly from autumn to spring.

The experimental area was on the steep side of a hill (Figure 1), adjacent to the main valley of the catchment area. The hillslope faces north and has a mean elevation of $63 \mathrm{~m}$ a.s.l. It is about $60 \mathrm{~m}$ long with a mean gradient of $30 \%$. At the top of the hillslope, incoming overland flow and subsurface flow are diverted by the ditches alongside a road. At the bottom the slope is drained by the incised stream of the main river of the catchment area. Two adjacent $60 \mathrm{~m}$ long by 15 $\mathrm{m}$ wide sites on the hillslope with different land uses were selected for the research. One site was covered with a well-developed mediterranean maquis and the other was an unmanaged area covered with spontaneous grass. The maquis is 2-4 m high and consists of dense evergreen shrubs such as Myrtus Communis L., Arbutus unedo L., Erica arborea L., Phillirea latifolia L. and Pistacia lentiscus L.. The spontaneous grass area (Hordeum spontaneoum L., Avena sativa L., Galactites tomentosa Moench, etc.) is at least 10 years old. It is the result of clearing the previous maquis and the deep plowing (only once after the maquis had been cleared) to create a $15 \mathrm{~m}$ wide firebreak. The soil in both sites is about 0.4-0.5 m deep and overlies a greyish, altered substratum of Permian sandstone. This latter is very dense (at least $1900 \mathrm{~kg} \mathrm{~m}^{-3}$ ), and drainage through it is very low, which prevents deep percolation. Soils are classified as Lithic Haploxerepts. The soil horizons include A, Bw and $\mathrm{C}$ in the area covered in maquis, and $\mathrm{Ap}, \mathrm{BW}$ and $\mathrm{C}$ in the area covered in grass. Because the two areas have the same climate and topographical features, they appear suitable for a comparative investigation of the effects of land use on soil hydrology.

\section{Soil sampling, physical and hydrological property measurements}

Measurements of the physical and hydrological properties of the soil were carried out in both classes of land use at randomly chosen sites in the hillslope, at least $5 \mathrm{~m}$ inside the border of the maquis cover and close the central transect of the grassy zone. The litter and leaf residues (about $10 \mathrm{~cm}$ thick in the maquis and $1 \mathrm{~cm}$ thick in the grassed area) were removed from the soil surface before measurements were taken. Soil core samples were taken, so that the textural characteristics and organic matter content (OM), soil bulk density $\rho_{b}$ and the water retention characteristics $\theta(h)$ of the soil could be analysed in the laboratory. The saturated and unsaturated hydraulic conductivity of the soils, $K_{f s}$ and $K(h)$, were also estimated in the field. Soil sampling and hydrological measurements were carried out at depths of $0.1 \mathrm{~m}$ (topsoil) and $0.2 \mathrm{~m}$ (subsoil) below the exposed soil surface, with the exception that $K(h)$ was only estimated in the topsoil. The soil sampling was limited to a maximum depth of $0.2 \mathrm{~m}$ because, as several investigations have reported (Celik, 2005; Zimmermann et al., 2006; Hassler et al., 2010), the effects of land use decreases as the soil depth increases. Measurements were taken in June 2012 and, in the case of $K_{f s}$, were repeated in February 2013. All the field measurements were taken during a two-week rainless period. This minimised the effect of changes in soil moisture on the 
hydraulic properties of the soil over time.

The clay, silt, and sand content in 16 disturbed soil samples were determined, according to the United States Department of Agriculture (USDA) classification, by sieving for coarse and fine sand and by the pipette method for the silt and clay soil fractions. The 0M was estimated to be equal to 1.724 times the organic carbon content. This was determined by the Walkley-Black method (Sleutel et al., 2007). The $\rho_{b}$ was estimated in the laboratory by oven-drying $\left(110^{\circ} \mathrm{C}\right.$ for $\left.48 \mathrm{~h}\right) 60$ soil samples in steel cylinders $\left(5 \mathrm{~cm}\right.$ high, volume of $\left.100 \mathrm{~cm}^{3}\right)$.

$\theta(h)$ were estimated using data from evaporation experiments on soil samples in the laboratory, using experimental procedures described in Pirastru and Niedda (2010). Soil core samples were collected in the field by pushing $10 \mathrm{~cm}$ high PVC cylinders with a volume of $300 \mathrm{~cm}^{3}$ into the soil surface. The cylinders had a sharp cutting edge, so that they could be inserted with the minimum disturbance to the soil. Care was taken to insert the cylinders in soil areas which seemed to be free of stones. If the soil core samples included stones, the data was discarded. Eight soil core samples, 4 from each site, were used for the experiments. This number of samples is thought to be enough to obtain a sample mean that is within $25 \%$ of true mean at a $90 \%$ confidence level, because it is expected low or medium variability in the amount of water retained at different tension levels (Warrick, 1998).

A single-ring infiltrometer was used to estimate $K_{f s}$ in 96 field-infiltration experiments (Reynolds et al., 2002; Bagarello et al., 2014). A horizontal step was created in the sloping surface, to allow this instrument to be installed. The steel cylinder $(10 \mathrm{~cm}$ in diameter $)$ was inserted down to the prescribed soil depth, and a constant water pressure head $(3 \mathrm{~cm})$ was established within the cylinder above the soil, using a Mariotte bottle device. Once an apparent steady-state flow had been reached (at least thirty minutes after the start of each experiment), the outflow was manually recorded every 5 min for a period of $30 \mathrm{~min}$, and the steady outflow rate was calculated by averaging these results.

In the moisture range close to water saturation the $K(h)$ was estimated with a tension infiltrometer apparatus such as that illustrated in Angulo-Jaramillo et al. (2000). The measurements were taken at only 10 locations, because of the difficulties encountered when the tension infiltrometer was installed in the field. These difficulties were due to the steepness of the slope, the stoniness of the soil and, for the maquis, the inaccessibility of the undergrowth. However, in the scientific literature (Gajić, 2013; Castellini and Ventrella, 2012; Das Gupta et al., 2006; Zhou et al., 2008; Hassler et al., 2010) similar sized data sets have been found to be sufficient for highlighting the effects of land use and soil management on the hydraulic conductivity of the soil. A horizontal step was created in the sloping surface, to allow the tension infiltrometer to be installed. Details about the used experimental procedure can be found in Castellini and Ventrella (2012). The infiltration rates were measured by applying the dry to wet sequence of water pressure heads of $h=-10,-5,-3$ and $-1 \mathrm{~cm}$ at the same soil site, in order to exclude any confusion in the results due to hysteresis (Bagarello et al., 2005). The outflow rate was calculated by averaging the 5 min measurements, after an apparent steadystate flow had been reached.

\section{Analysis of data}

Data from evaporation experiments in the laboratory were analysed using the mathematical procedures described in detail in Arya (2002) and Pirastru and Niedda (2010). The resulting water retention data from each experiment were fitted to the van Genuchten (VG) parametric function (van Genuchten, 1980), using the RETC non-linear least squares curve-fitting program (van Genuchten et al., 1991), and assuming that the residual water content was zero:

$$
\theta(h)=\left\{\begin{array}{cc}
\theta_{s} & h<0 \\
\frac{\left.1+|\alpha h|^{n}\right]^{1-1 / n)}}{\theta_{s}} & h \geq 0
\end{array}\right.
$$

where:

$\alpha\left[\mathrm{cm}^{-1}\right], n[-]$ and $m[-]$ are shape factors that depend on soil type, $h$ is the water pressure head $[\mathrm{cm}]$ in the soil.

The $K_{f s}$ values were calculated from the steady-state infiltration rate measured during the infiltration experiments, using the singlehead analysis described by Reynolds and Elrick (2002). In this analysis the parameter $\alpha^{*}$ was set at $12 \mathrm{~m}^{-1}$, which is adequate for most structured soils (Elrick and Reynolds, 1992).

The $K(h)$ values were calculated from steady-state outflow rate by means of the double tension approach described by Reynolds and Elrick (1991) and Bagarello et al. (2010). We used the Wooding (1968) analytical solution for steady-state flow from a circular source, written for two different hydraulic heads and the two corresponding water volume flow infiltration rates.

All the measurements from the same soil depth were pooled for each land use class. The arithmetic mean (M) and the coefficient of variation (CV) were used to describe the data. The geometric mean (GM) and the appropriate equation for CV were used to describe the $K_{f s}$ data, because they are better described by a log-normal distribution (Lee et al., 1985).

Non-parametric Mann-Whitney Rank Sum tests were performed to test for the significance of the differences in the soil properties of the topsoil and the subsoil in the different land use classes. A threshold value of $\mathrm{P}=0.05$ was used to define statistical significance. All analyses were performed using the functions of the MATLAB Statistical Toolbox (Natick, MA, USA).

\section{Hydrological monitoring setup}

Two identical sets of instruments, one set within the maquis, and the other in the area covered with grass, were installed in January 2009 (Figure 1). Each set included three TDR Campbell Scientific Inc. (Logan, UT, USA) CS216 Water Content Reflectometers (two-rod model, $0.3 \mathrm{~m}$ rod-length and $32 \mathrm{~mm}$ spacing) to measure moisture and one termistore (Model 107 Temperature Probe) to measure soil temperature. The termistore was located at a depth of $0.15 \mathrm{~m}$. Two TDR probes were inserted horizontally at depths of 0.1 and $0.2 \mathrm{~m}$, in order to monitor rapid soil moisture changes in the topsoil in more detail. A third TDR probe was placed $0.3 \mathrm{~m}$ deep in the soil. This was installed approximately vertically, and was done to monitor the average soil moisture of the subsoil at depths between $0.3 \mathrm{~m}$ and $0.5 \mathrm{~m}$ (this will be referred to hereafter as the intermediate depth of $0.4 \mathrm{~m}$ ). The output signals of the TDR probes were adjusted for soil temperature following the manufacturer's instructions. In order to calibrate the probe, the output signals were related to independently determine volumetric water contents in the field. From these data it was possible to describe the probe response to changing water content by the quadratic calibration equation:

$\theta_{\mathrm{v}}=\mathrm{C}_{0}+\mathrm{C}_{1} * \tau+\mathrm{C}_{2} * \tau^{2}$

where:

$\theta_{\mathrm{v}}$ is the volumetric water content $\left(\mathrm{cm}^{3} \mathrm{~cm}^{-3}\right)$;

$\tau$ the $\mathrm{CS} 616$ period ( $\mu \mathrm{s})$; and

$\mathrm{C}_{0}, \mathrm{C}_{1}$ and $\mathrm{C}_{2}$ are calibration coefficients derived from the curve fit $\left(\mathrm{R}^{2}=0.93\right)$. 
All the automatic measurements were executed every $5 \mathrm{~min}$ in order to also monitor the fastest soil moisture changes, and were simultaneously logged by a Campbell Scientific Inc. CR1000 data logger.

Three shallow observation wells were installed in the maquis site (M1, M2 and M3 of Figure 1) and five in the grassed site (from G1 to G5 of Figure 1) in January 2009, in order to monitor the height of the perched water table that developed within the soil above the impeding layer of altered sandstone. Each observation well extended down to the impeding layer, and was screened $0.3 \mathrm{~m}$ above the top of this layer. The height of the perched water table was monitored manually by a phreatimeter during site visits throughout the winter and spring of 2009. The time interval for monitoring varied, ranging from one day, after rainfall events, to ten days, in rainless periods.

Additional hydrological monitoring was carried out at the maquis site, beginning in autumn 2012. This included using two pressure transducers (Schlumberger mini-diver) to measure the water table heights in M2 and M3 every 5 min, while M1 was monitored manually during site visits. Throughfall was also estimated in the area covered in maquis, using three tipping bucket rain gauges located close to M2. These measurements were compared with those for gross rainfall, measured by the tipping bucket rain gauge of an automatic weather station. This was installed in January 2009, about $300 \mathrm{~m}$ away from the hillslope.

\section{Results}

\section{Physical and hydrological soil properties}

\section{Soil texture and organic matter content}

Thirteen of the 16 soil samples analysed were classified as sandy loam. The other three were sandy clay loam, one coming from the grassy soil, and two from the maquis soil. As can be seen from Table 1 , the mean percentages of sand, silt and clay of topsoil and subsoil were very similar in the grassed site, and differed slightly in the maquis site. This was because the topsoil in the latter was richer in clay. The mean percentages of sand, silt and clay in the topsoil and subsoil were statistically similar.

As shown in Table 1, in the maquis site the mean OM of the topsoil was 1.62 times greater than that of the subsoil. This vertical difference was not so apparent in the grassed site, with the mean $0 \mathrm{M}$ being similar at depths of 0.1 and $0.2 \mathrm{~m}$. The mean $0 \mathrm{M}$ of the topsoil in the maquis site was 3.1 times greater than that of grassy site, and the difference between land use classes was statistically significant. The mean $\mathrm{OM}$ of the subsoil in the maquis site was 2.6 times greater than of that grassy site and, once again, the difference was statistically significant.

Table 1. Physical soil properties (mean values) at depth of 0.1 and $0.2 \mathrm{~m}$ in the maquis and grassed sites.

\begin{tabular}{lcccc} 
& \multicolumn{2}{c}{ Maquis* } & \multicolumn{2}{c}{ Grass $^{*}$} \\
Soil depth increment & $0-0.1 \mathrm{~m}$ & $\mathbf{0 . 1 - 0 . 2} \mathrm{m}$ & $\mathbf{0 - 0 . 1} \mathrm{m}$ & $0.1-0.2 \mathrm{~m}$ \\
\hline $\begin{array}{l}\text { Sand \% } \\
(\mathrm{n}=4)\end{array}$ & 61.1 & 66.6 & $68.6^{\text {aa }}$ & $67.0^{\text {aa }}$ \\
Silt \% & $(0.18)$ & $(0.11)$ & $(0.06)$ & $(0.18)$ \\
$(\mathrm{n}=4)$ & 20.2 & 21.6 & $14.9^{\mathrm{aa}}$ & $14.4^{\mathrm{aa}}$ \\
\hline Clay \% & $(0.28)$ & $(0.37)$ & $(0.06)$ & $(0.36)$ \\
$(\mathrm{n}=4)$ & 18.7 & 11.8 & $16.5^{\mathrm{aa}}$ & $18.6^{\mathrm{aa}}$ \\
$\mathrm{OM} \%$ & $(0.29)$ & $(0.16)$ & $(0.19)$ & $(0.45)$ \\
$(\mathrm{n}=4)$ & 14.3 & 8.80 & $4.60^{\mathrm{ab}}$ & $3.30^{\mathrm{ab}}$ \\
\hline$\rho_{b}\left(100 \mathrm{~cm}^{3}\right) \mathrm{g} \mathrm{cm}^{-3}$ & $(0.09)$ & $(0.33)$ & $(0.21)$ & $(0.31)$ \\
$(\mathrm{n}=15)$ & 1.14 & 1.39 & $1.57^{\mathrm{ab}}$ & $1.62^{\mathrm{ab}}$ \\
\hline
\end{tabular}

*In parentheses are showed the coefficients of variation. Different letters indicate that the soil property value in the grassed soil significantly $(\mathrm{P}<0.05)$ differs respect to that of the maquis soil.
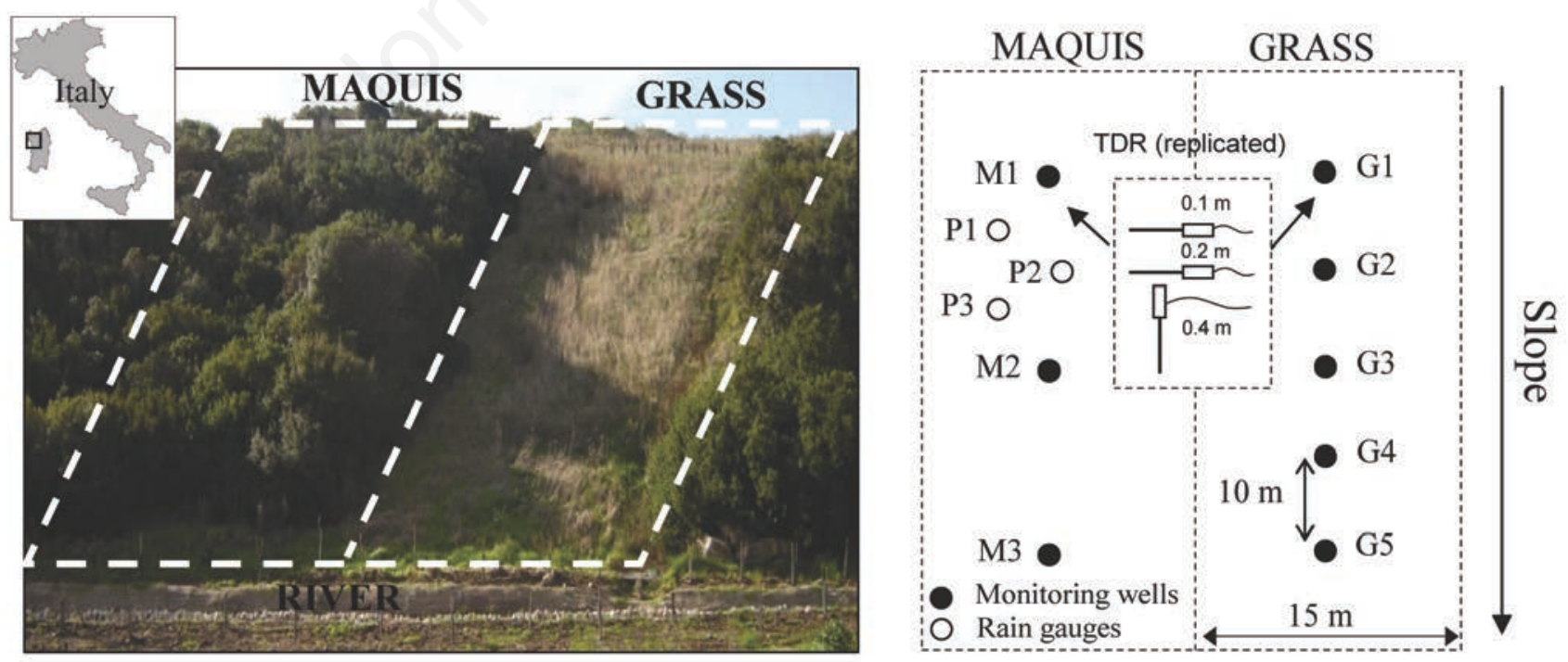

Figure 1. Photograph of the experimental hillslope with the maquis and grassed areas, and illustration of the monitoring design including automatic TDR probes, shallow piezometers and the rain gauges below the maquis cover for the throughfall estimation. 


\section{Soil bulk density}

In the maquis site the mean $\rho_{b}$ of the topsoil $\left(1.14 \mathrm{~g} \mathrm{~cm}^{-3}\right)$ was about $80 \%$ of that of the subsoil. By contrast, in the grassed site the mean $\rho_{b}$ of the topsoil and of the subsoil were very similar (Table 1). This reflects the above mentioned lack of variance in $0 \mathrm{M}$ along this profile. The mean $\rho_{b}$ of the maquis topsoil was $72 \%$ of that of the grassed topsoil. The mean $\rho_{b}$ of the maquis subsoil was $85 \%$ of that of the grassed subsoil. The differences between the land use classes were statistically significant at both depths.

\section{Water retention characteristics}

Figure 2 shows the water retention data obtained from the evaporation experiments for the two investigated soils. In the Figure 2 are showed the mean water retention curves, obtained by pooling all the retention data from each soil and then fitting them, using the VG equation (Eq. 1).

Fitting the van Genuchten equation separately to the retention data from each evaporation test gave $\mathrm{R}^{2}$ values always greater than 0.97 . The values of the $n$ parameter varied over approximately the same narrow range of values $(1.13>n>1.21$ in grassy soil, $1.13>n>1.28$ in maquis soil). This parameter is mainly the result of the slope of the retention curve at low potentials $(h<-300 \mathrm{~cm})$ and varies little among soils, as can be seen in Figure 2.

There was greater variation in the $\alpha$ values for the two soils $(0.06>\alpha>0.74$ in the maquis site, $0.03>\alpha>0.16$ in the grassed site). This complicated the identification of differences between the maquis and grassed soils. We used the fitting strategy illustrated in Schwartz et al. (2003) to reduce this variation. We fixed the value of $n$ at the observed mean value $(n=1.19)$, and carried out a one-parameter fit for each land use. As it did in Schwartz et al. (2003), this approach improved the identification of $\alpha$, while not compromising the fit of the measured retention data $\left(R^{2}>0.95\right)$. When this fitting strategy was used, the $\alpha$ parameters were consistently greater for the maquis site $(0.16>\alpha>0.23)$ than for the grassed site $(0.03>\alpha>0.079)$.

\section{Unsaturated and saturated hydraulic conductivity}

As can be seen from Figure 3, for $h=-10,-5-,-3$ and $-1 \mathrm{~cm}$, the mean $K(h)$ in the maquis site were about $2.1,3.1,2.7$ and 1.2 times greater than those for the grassed site. The $K(h)$ values in the maquis soil and in the grassy soil increased at about the same rate, passing from $h=-10 \mathrm{~cm}$ to $\mathrm{h}=-3 \mathrm{~cm}$. For water tensions greater than $\mathrm{h}=-3$ $\mathrm{cm}$, the rate of increase in the grassy soil was about double that of the maquis soil.

The $K_{f s}$ in the summer ranged from 130 to $600 \mathrm{~mm} \mathrm{~h}^{-1}$ in the maquis site, and from 9.5 to $390 \mathrm{~mm} \mathrm{~h}^{-1}$ in the grassed site. As shown in Table $2, K_{f s}$ decreased rapidly with depth, with the $K_{f s}$ of the topsoil being about 1.76 greater than that of the subsoil in the maquis and 2.4 times greater in the grassed site. Table 2 shows that the average $K_{f s}$ in the topsoil of the maquis site was about 1.75 times higher than that of the grassed site. The average $K_{f s}$ in the subsoil of the maquis site was about 2.4 times higher than that of the grassed site. At the two investigated soil depths, the null hypothesis that there was no difference between land uses cannot be rejected.

In the winter period, the $K_{f s}$ values ranged from 117 to $2154 \mathrm{~mm} \mathrm{~h}^{-}$ 1 in the maquis site and from 25 to $378 \mathrm{~mm} \mathrm{~h}^{-1}$ in the grassed site, and. High values, such as those that we found on several occasions in the maquis soil, have been reported in the scientific literature in both agricultural soils (Etana et al., 2013; Castellini et al., 2014) and forested soils. For example, Gonzalez-Sosa et al. (2010) in their study on a small wood with ivy land use measured a mean $\mathrm{K}_{\mathrm{fs}}$ of $5400 \mathrm{~mm}$ $\mathrm{h}^{-1}$ with a single ring infiltrometer. Even higher values were found by
Buczko et al. (2006), who used a ponded ring infiltrometer in a study on soil water repellence in forest soils. Based on the winter measurements, the $K_{f s}$ of the topsoil in the maquis site was about 2.8 times higher than that of the subsoil, while $K_{f s}$ varied 1.5 times with depth in the grassed site (Table 2). The average $K_{f s}$ of the maquis topsoil

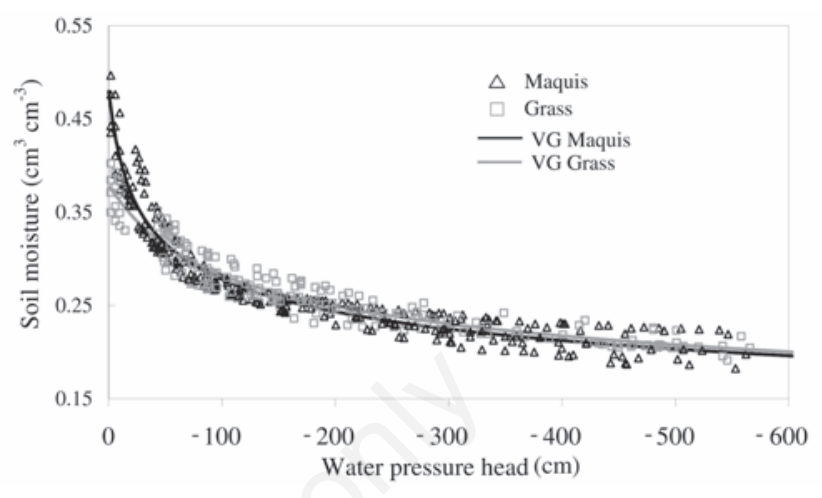

Figure 2. Ensemble of the water retention point data obtained in the evaporation experiments in laboratory for the maquis and grassed soils, and fitted van Genuchten (VG) curves. For the curve fitting the parameter $n$ was fixed to the averaged value $\mathrm{n}=1.19$ (see text for more details). Other fitting parameters are: for maquis site $\theta_{s}=\mathbf{0 . 4 8}$ and $\alpha=\mathbf{0 . 1 5 3}$, for grassed site $\theta_{s}=\mathbf{0 . 3 8}$ and $\alpha=\mathbf{0 . 0 3 3}$.

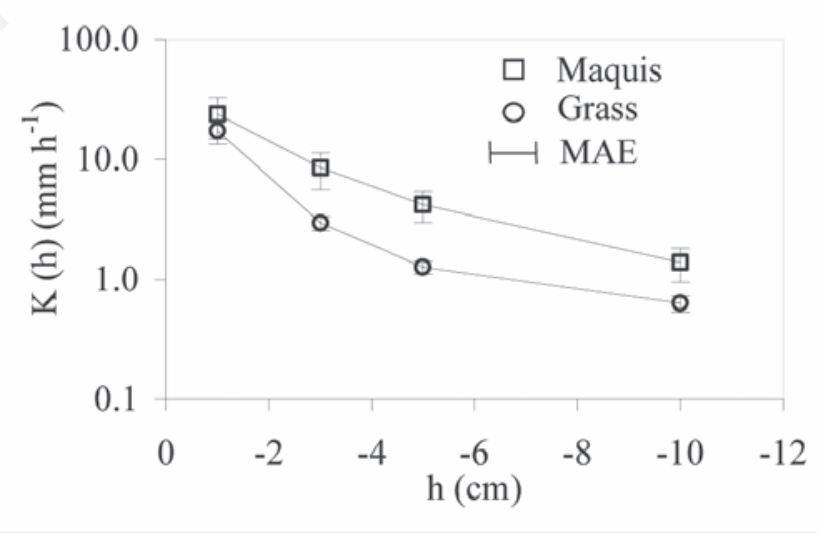

Figure 3. Mean values and mean absolute errors (MAE) of $K(b)$ estimated in the summer at the water tensions of $-10,-5,-3,-1$ $\mathrm{cm}$, in the maquis and in the grassed soils.

Table 2. $K_{\mathrm{fs}}$ values measured in the summer and in the winter seasons in the topsoil and subsoil of the maquis and grassed sites (sample size $\mathbf{n}=12$ ).

\begin{tabular}{lcccc} 
& \multicolumn{2}{c}{ Maquis* } & \multicolumn{2}{c}{ Grass* $^{*}$} \\
Soil depth increment & $0-0.1 \mathrm{~m}$ & $0.1-0.2 \mathrm{~m}$ & $0-0.1 \mathrm{~m}$ & $0.1-0.2 \mathrm{~m}$ \\
$\mathrm{Kf}_{\text {summer }}\left(\mathrm{mm} \mathrm{h}^{-1}\right)$ & $445(0.25)$ & $253(0.59)$ & $254^{\mathrm{aa} \circ}(0.51)$ & $105^{\mathrm{aa} \circ}(1.29)$ \\
$\mathrm{Kf}_{\text {winter }}\left(\mathrm{mm} \mathrm{h}^{-1}\right)$ & $1017(0.63)$ & $363(0.52)$ & $139^{\mathrm{abo}}(0.7)$ & $94^{\text {abo }}(0.54)$ \\
\hline $\mathrm{GM}_{\text {winter }} \mathrm{GM}_{\text {summer }}^{\#}$ & $2.28^{\mathrm{cd} \#}$ & $1.433^{\mathrm{cd} \#}$ & $0.55^{\mathrm{cc} \#}$ & $0.89^{\mathrm{cc} \#}$ \\
\hline
\end{tabular}

GM, geometric means. *In parentheses are showed the coefficients of variation; ${ }^{\circ}$ Different letters indicate that the $\mathrm{K}_{\mathrm{fs}}$ of the grassed soil significantly $(\mathrm{P}<0.05)$ differs respect to that of the maquis soil; "Different letters indicate that the $\mathrm{K}_{\mathrm{fs}}$ significantly $(\mathrm{P}<0.05)$ changed from summer to winter season. 
was about 7.3 times higher than that of the grassed site. In the subsoil, the average $K_{f s}$ of the maquis was about 3.9 times higher than that of the grassed site. The statistical analysis indicated that there were significant differences between land uses at the two investigated soil depths.

\section{Near-surface soil water dynamics}

\section{Throughfall}

The data for the throughfall observed in the wet season 2012-2013 by the three rain gauges installed under the maquis cover are shown in Figure 4A, and compared with the gross rainfall measured at the weather station. The data are complete for pluviometers P1 and P2, while for the third pluviometer P3 data stops in February 2013, because this instrument was irreparably damaged.

Throughfall was $68 \%$ of the gross rainfall for P1, $76 \%$ for P2 and $55 \%$ for P3. The average throughfall (the average of P1 and P2) was about $70 \%$ of the gross rainfall for the whole monitoring period. This data is in line with the values reported for Mediterranean environments in the review by Llorens and Domingo (2007).

\section{Soil moisture}

The temporal dynamics of the soil moisture at depths of $0.1,0.2$ and
$0.4 \mathrm{~m}$ in the maquis and grassed sites were observed from January 2009 to September 2010. The period included two wet seasons and one dry season (Figure 5A). These data are shown in Figure 5B and $\mathrm{C}$. The water storage levels were estimated for the different land uses and showed in Figure 5D. The soil storage was computed by assuming that the horizontal probes estimated the average soil moisture in first $0.3 \mathrm{~m}$ of soil, and that the vertical probes did the same for the remaining soil volume until the impeding layer. The maximum water storage was about $180 \mathrm{~mm}$ for the grass and $140 \mathrm{~mm}$ for the maquis soil, with little difference between the two wet seasons that we monitored. The minimum stored water in the 2009 dry season was about $55 \mathrm{~mm}$ in the grass and $60 \mathrm{~mm}$ in the maquis. In the autumn of $2009,180 \mathrm{~mm}$ of rainfall recharged the water storage of the grassy soil of about 125 $\mathrm{mm}$. This was mainly due to the rain events of 15 September and 22 October 2009. In the same period the recovery of the soil water storage below the maquis was more gradual and ended in winter, when overall the soil water storage increased of about $80 \mathrm{~mm}$. In early spring increasing evapotranspiration caused the soils to start to dry out, first under the maquis and then under the grass. However, as the dry season advanced, the soil depletion rate was very intense in the grassy site and in the summer of 2009 the situation for the moisture levels in the soils was reversed, with the grassy soil being drier than the maquis soil.
A

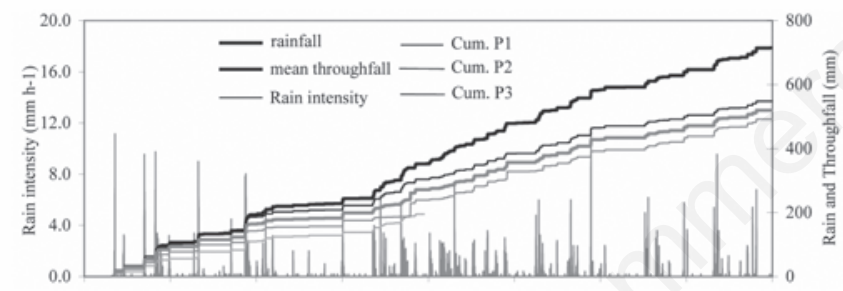

B

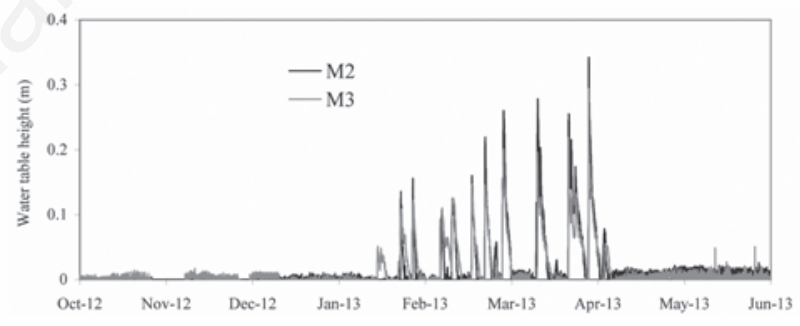

Figure 4. Observed rainfall and throughfall below the maquis cover (A) and hydrographs (B) showing the perched water table heights measured above the impeding layer in the piezometers M2 and M3 during the rainy season 2012-2013.

A

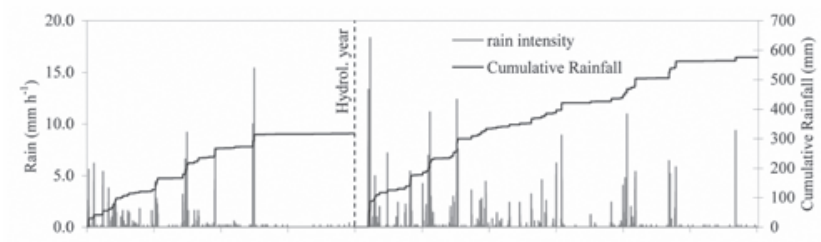

B

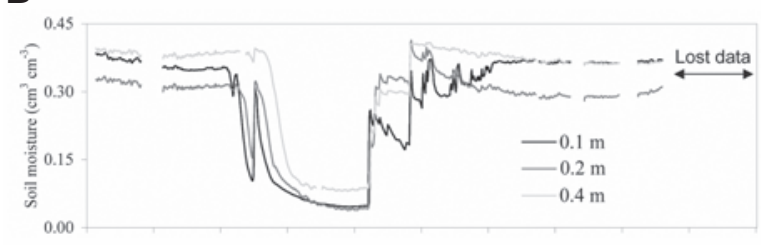

C

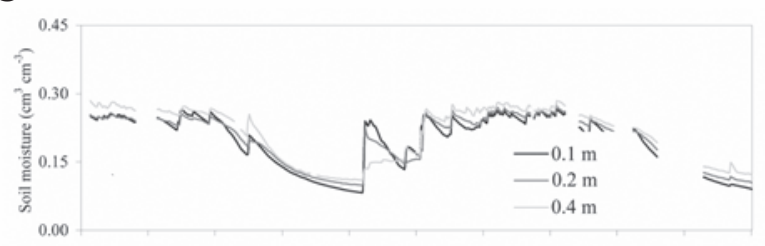

D

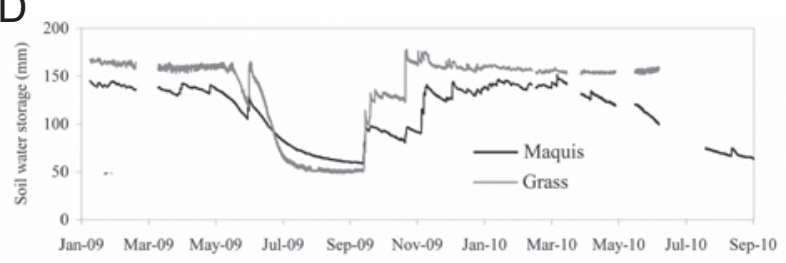

Figure 5. Observed rainfall (A), soil moisture at $0.1,0.2$ and $0.4 \mathrm{~m}$ of depth, observed from the January 2009 to September 2010 in the grassed site $(B)$ and in the maquis site $(C)$, and computed soil water storage (D). 
The TDR data indicated that at the three monitored soil depths the dynamics of soil moisture over time was different in the two soils. At the beginning of autumn 2009 the TDR probes in the grassed site reacted to the intense rainfall events simultaneously at all the observed soil depths, and these responses occurred a short time (a few minutes) after the beginning of the rain. These rain events, increased the moisture at depths of 0.2 and $0.4 \mathrm{~m}$ of soil by about $20 \%$, and this increase was greater than that in the surface layer. Afterwards, the water content at 0.2 and $0.4 \mathrm{~m}$ of depth stayed mainly constant until the rain event of 22 October 2009 , which saturated the soil at these depths. During the rainy autumn of 2009 the water content of the soil at $0.1 \mathrm{~m}$ of depth fluctuated more than did that of the deepest soil layer. This was due to the drainage through the superficial cracks and to the evapotranspiration process. In the winter evapotraspiration was low and the cracks in the soil closed, greatly reducing its conductivity. As a result, from January 2010 the water in the topsoil started to stagnate.

The TDR responses in the maquis site during the rain events of September and October 2009 were less apparent than those in the grassed site. These responses lessened with depth, so that the TDR probe at $0.4 \mathrm{~m}$ of depth was only slightly affected by these rains. As the wet season advanced soil moisture became more evenly distributed in the soil profile, and, from the beginning of the winter, it approached the maximum annual values at all depths.

The soil of the grassy site at a depth of $0.1 \mathrm{~m}$ was always close to saturation in the two observed winter periods. This agreed with the evidence of a very shallow groundwater table from piezometer G1 nearby (Figure 6). This was measured directly in the winter of 2009, but was also found throughout the winter of 2010 . However, although the water table submerged the 0.2 and $0.4 \mathrm{~m}$ deep TDR probes in both the winters, in these periods the observed soil moisture at the same soil depths was $70 \%$ and $85 \%$ of saturation, respectively. As can be seen from the results for the winter of 2010 , these values were reached gradually, after peak levels that were the result of intense rain events in the autumn. We believe that this progressive reduction in moisture at 0.2 and $0.4 \mathrm{~m}$ of depth from the beginning of the wet season was due to the changes in the soil structure over time. Because the soil was wet, the soil aggregates may have expanded. This may have closed some large cracks near the probe rods, thus reducing the amount of retained water.

In the two observed winter periods the mean water content of the maquis soil was always close to $50 \%$ of saturation. This value approximately matches the field capacity of this soil (i.e. water held at -333 $\mathrm{cm} \mathrm{H}_{2} \mathrm{O}$, Figure 2). After this soil moisture condition was reached, each rain event in the winter increased soil moisture by no more than $2-3 \%$, without ever saturating the soil. The infiltrated water was then

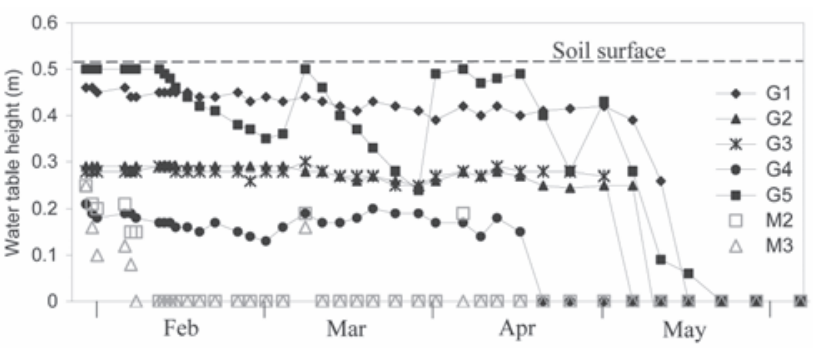

Figure 6. Hydrographs showing the observed perched water table heights above the impeding layer in the maquis and grassed sites in the rainy season 2009 . rapidly redistributed by the efficient drainage in the soil.

The hydrological behavior of the two soils was also different in the dry periods of spring-summer 2009. In the grassed site the drying process started on the surface and then deeper down. It was very intense at all depths, so that by the start of the summer the soil moisture level already approached the minimum water content level for the year. In the maquis site the soil dried out more gradually than it did in the grassed site, so that at the end of summer the drying process still did not seem to have been completed. This process also occurred almost simultaneously at all depths.

\section{Perched water table}

The results of monitoring the shallow groundwater levels at the maquis and grassed sites during the rainy season of 2009 are shown in Figure 6. During this period all the piezometers of the grassed site showed that there was a perched water table. The water table persisted throughout the winter, and then disappeared at the beginning of the summer. The water table levels were close to the soil surface at piezometers G1 and G5, which were positioned, respectively, at the top and bottom of the slope, and were deeper at G2, G3 and G4, in the central part of hillslope. The observed levels at G1, G2, G3 and G4 varied by a few centimetres, without ever reaching the surface of the soil. However, because our measurements were relatively infrequent, we cannot exclude the possibility that levels peaked at the soil surface during the most intense rainfall. In G5 the level fluctuations were greater and for long periods the levels rose to the soil surface.

During the rainy season of 2009 a perched water table was observed in wells M2 and M3 in the maquis site, but not in M1. This occurred for ten days at the beginning of the monitoring period, and also after the rainfall events of 7 March and 4 April 2009. On these occasions the groundwater table dried up before the subsequent visit to the site, which was four days later. During all site visits the monitored water table never reached the surface of the soil.

Monitoring of the groundwater levels in M1, M2 and M3 was carried out also from October 2012 to June 2013. No piezometric responses were observed in $\mathrm{M} 1$ throughout the monitoring period. In M2 and M3 no piezometric responses were observed in the autumn, but, unlike in the rainy season of 2009 , on several occasions a perched water table developed in both these wells. This started in January 2013, as shown in Figure 4B. Levels begin to rise from one to three hours after the start of the rain, and then took from between one and twelve hours to reach their peak. In neither well did the water table reach the surface of the soil. After the rain ceased, the perched water table took from three to six days to dry out.

\section{Discussion}

\section{Physical and hydrological soil properties}

Particle size analysis indicated that was no difference in the texture of the soil in the different land use areas. It indicates that the differences in the hydraulic properties of the soil and in the related hydrological processes in the maquis and the adjacent grassed area of the research site can be ascribed to the different vegetation types and the methods used to convert the land from one use to another, i.e. the deep ploughing that was carried out immediately after the maquis had been cleared. This occurred at least 10 years ago.

$\mathrm{OM}$ analysis indicated that the maquis cover creates much more favourable conditions for producing and storing $0 \mathrm{M}$ than does grass cover. These results are in line with the findings of several other studies in sites where forest and grassed areas are compared (Celik, 
2005; Gonzales-Sosa et al., 2010; Agnese et al., 2011). Because organic matter content distribution also influences $\rho_{b}$ of soil, as reported by many authors (Gajić, 2013; Agnese et al., 2011), there were significant differences in this soil property in the two different areas. The results of our study agree with those of other studies (Martinez and Zink, 2004; Gonzalez-Sosa et al., 2010; Price et al., 2010; Agnese et al., 2011), and support the general conclusion that after disruption of the natural land cover one must expect an increase in $\rho_{b}$, and this is more apparent in the topsoil than the subsoil.

Changes in land use altered the soil pore size distribution. Analysis of the water retention characteristics of the soils suggested that these changes were limited to the water tension range from saturation to $50 \mathrm{~cm}$. From Figure 2 one can see that in this range in mean the retained water content of the maquis soil greatly exceeded that of the grassed soil. Based on the water retention curves, we calculated that in the range from saturation to $-5 \mathrm{~cm}$ of tension, where macropores are able to conduct the flow (Messing and Jarvis, 1993), the retained water was $4 \%$ in the maquis site, and $0.7 \%$ in the grassed site. Similar ranges of porosity were also found by Agnese et al. (2011), Daraghmeh et al. (2008) and Schwartz et al. (2003). When the soil is far from saturation $(\mathrm{h}<-50 \mathrm{~cm})$, water retention is mainly affected by the micropore, which, in turn, is mainly determined by the soil texture (van Genuchten and Nielsen, 1985). Because this was similar among the observed soils, this similarity was mirrored in the water retention characteristics at the lowest potentials. For modelling purposes a decrease in the van Genuchten parameter $\alpha$, rather than $n$, may better represent the alterations in the pore size distribution in the grassy soil.

The $K(h)$ measurements in both maquis and grassed sites increased more than one order of magnitude passing from $h=-10 \mathrm{~cm}$ to $h=-1 \mathrm{~cm}$. The greater variability in $K(h)$ in the maquis site is an indication of the higher spatial variation of the biopores (e.g. tree roots and worm holes) in this soil. However one difference was observed in the way in which these flow paths were activated in the two soils during the infiltration tests. As can be seen in Figure 3, for potentials higher than $-3 \mathrm{~cm}$, the slope of the $K(h)$ curve increase more for the grassed site than for the maquis site. This effect was due to the hydraulic activation of some cracks, which had been observed in the grassy topsoil during the dry summer. The fact that the $K(h)$ of the two soils was similar at the highest applied potential during the tests with the tension infiltrometer suggests that these cracks act in a similar way to the macropores in the maquis soil, conducting a great deal of water vertically.

As also found by other authors in different environments (Bormann and Klaassen, 2008; Zhou et al., 2008; Hu et al., 2012), the analysis of $K_{f_{s}}$ indicated that in our experimental site this hydraulic soil property varies due to complex spatial and temporal dynamics. In the maquis soil the $K_{f s}$ in the topsoil was 2.3 higher in winter than summer, and about 1.4 higher in the subsoil (Table 2). Both these increases were statistically significant. In the grassed site the $K_{f s}$ in the topsoil in winter was about $55 \%$ of that of the summer, and was $89 \%$ in the subsoil, although the decreases were not statistically significant. These results are in line with those of other field studies, which have indicated that $K_{f s}$ varies with time, depending of seasonal biotic and abiotic factors. Bormann and Klaassen (2008) and Zhou et al. (2008) found that the surface hydraulic conductivity measured under pasture and cropland in late spring or summer was higher than that measured in wetter periods. These results were explained by the increase in surface soil macroporosity, which was itself due to the development of animal burrows and earthworm channels in the spring, and the appearance of desiccation cracks in the surface of the soil in the dry months. This well describes our grassed site, where during the dry summer some superficial vertical cracks developed in the topsoil, and these were activated during the infiltration tests. Because these cracks were more frequent in the topsoil than in the subsoil, there was a significant seasonal decrease in $K_{f s}$ as the depth increased. In fact, during the wet winter the expansion of soil aggregates caused the cracks to close, with a resulting decrease in hydraulic conductivity.

In the maquis site, the high OM content stabilises soil aggregates, and this guarantees that soil structure is more stable over time. Thus, as Bormann and Klaassen (2008) and Zhou et al. (2008) stated, soil structure dynamics should have a minimal impact on changes in the hydraulic soil properties over time. However, unlike to the abovementioned authors, we observed an increase in $K_{f s}$ from summer to winter, and, as shown in the Table 2 , this increase was more evident in the topsoil than in the subsoil. This difference may be due to the very different soil moisture conditions when the measurements were made, about $15 \%$ of mean soil moisture in the summer and about $35 \%$ in the winter. There was also evidence that during the summer measurement period there was a moisture gradient along the soil profile, with the topsoil being drier than the subsoil. Unlike in the winter, in the summer greater air content may have been trapped in the soil during the ponding phase of the experiments of infiltration. This may have occurred more in the dry topsoil than in the wetter subsoil. Trapped air bubbles disrupt the continuity of the pore network and increase the tortuosity of the flow. This decreases the subsurface flow rate during the infiltration tests.

\section{Soil moisture}

Soil water data shows that land use significantly influences the volume of water stored in the soil. During the wet seasons the maquis soil always had lower water storage than did the grassy soil. One key factor in this was the high power of interception of the maquis cover. Indeed the data of throughfall collected in the 2012-2013 wet season below the maquis, albeit based on only three rain gauges, indicate that about $30 \%$ of annual rainfall evaporates before it reaches the soil. The thick stratum of non-decomposed litter from the marquis is also an additional store of intercepted water. Another reason (described in more detail in the Near surface hydrological processes discussion paragraph) was the efficient lateral soil drainage in the marquis soil. This resulted in most of the infiltrated water moving rapidly down the slope, without increasing the amount of water stored in the soil. By contrast, we believe that in the monitored wet seasons evapotranspiration had a negligible impact on the different soil water storage dynamics of the maquis and the grassed site. Potential evapotranspiration in winter was, indeed, generally lower than $<1 \mathrm{~mm} /$ day (Pirastru and Niedda, 2013), the vegetation completely covered the soil in both sites, and water uptake was not limited by soil water availability. Thus there is no reason to believe that the evapotranspiration of the maquis and of the grass were completely different.

The different dynamics of the water depletion in the two soils in the spring and the summer of 2009 are a reflection of the different canopy architecture of the maquis and the grass. When compared to the grassy soil, in the maquis site the presence of tall plants and undergrowth increased the radiation interception, so that direct evaporation of water from the soil was reduced. The xeromorphic adaptations of the leaves of the plants in the maquis to the semiarid Mediterranean climate, that have been studied by several authors in sites close our research area (Rotondi et al., 2003), also minimise water consumption during prolonged dry periods (Rotondi et al., 2003; Spano et al., 2009). These factors prevented the maquis soil from drying out intensively, as was not the case for the grassed soil.

We monitored the soil moisture in the two soils at different soil depth, so that we could analyse the progress of the wetting front and 
thus identify the primary processes involved in water infiltration. The rapid and simultaneous responses of the TDR probes at different soil depths during the intense rainfall of autumn 2009 suggest that preferential flow may have occurred during these events. During rainfall the low permeable soil matrix at the soil surface rapidly saturated, and so water was diverted into the vertical cracks. Hydrophobic conditions in the very dry organic soil surface may also have promoted infiltration through preferential paths at the end of the summer, as also described in Dekker and Ritsema (2000) and Nimmo (2012). The cracks conducted water downwards, until it reached the impeding layer, and the high interaction with the soil matrix rewetted the soil profile from the bottom upwards.

In the maquis site the TDR reactions were frequently simultaneous at two or three depths, although sometimes the deepest probe reacted before the others. Progressive top-down front propagation, which is characteristic of matrix flow, appeared to be an exception. Similar behavior was observed by Alaoui et al. (2011) and Jost et al. (2012) during intense artificial rainfall tests in forested soil. The increase in soil moisture was generally greater on the surface than at depth, but cases where the response of the deepest probe was more apparent than that of the intermediate probe were not rare. The heterogeneous distribution of the wetting front is characteristic of the activation of preferential paths in the soil. Because the previous water content never exceeded the field capacity, we hypothesise that this process may begin at the soil surface. The surface macropore system transferred water down to the high permeable layers at the bottom of the profile. As the water travels down, interaction with the surrounding soil matrix caused the matrix to moisten, but, depending on drainage rate and local wall permeability, some water may escape, bypass the pores and reach the deepest soil layer.

\section{Perched water table}

Our research indicated that the change in land use altered the groundwater dynamics in the grassed site. The perched water table persisted throughout the monitoring period in the grassed site in the winter and spring 2009, which were seasons with below average rainfall, while in the same periods the water table was only rarely observed below the maquis. However in the winter and spring of 2013 frequent short-lived and event based water table rises were observed in the maquis site, due to the above average rainfall. In fact, in the winter and spring of 2013 there were $490 \mathrm{~mm}$ of rain, compared to 270 $\mathrm{mm}$ for the same period in 2009. Moreover, in 2013 rain events were frequent, and this resulted in persistently high soil moisture levels. As a consequence, even modest water inputs were enough to saturate the lowest soil layers. Similar differences in piezometric responses were detected by Germer et al. (2010) in their comparative study of land under forest and pasture in the Amazon basin. They connected these differences to the worsening of the hydraulic properties of the soil after land use change. De Moraes et al. (2006) in the same context came to the same conclusion, but also claimed that the lower water uptake of grassland when compared to forests was part of the reason for this. Rockefeller et al. (2004) also detected an increased height and persistence in the water table in a deforested area, when compared to pasture. They attributed this to the larger interception and evaporation rate of the forest when compared to pasture. Schume et al. (2004) also found that canopy interception is an important source of the variations in the hydrological behavior of soils under different tree species during the growing season.

\section{Near-surface hydrological processes}

In the maquis site, analysis of the TDR probe responses at the various soil depths suggested that rainfall mainly infiltrated vertically through the preferential pathways, bypassing the soil matrix. The low vegetation cover and the thick litter stratum protect the soil surface and aggregates from the impact of raindrops, and this ensures the stability over time of the macropore system, with respect to surface sealing effects. All the $K_{f s}$ values measured in the topsoil greatly exceeded the maximum 5 -min rainfall intensity $\left(130 \mathrm{~mm} \mathrm{~h}^{-1}\right)$ recorded in the years 2009-2013. Although the measured $K_{f s}$ value may underestimate surface infiltrability, this suggests that all the rain infiltrated, even during the most intense events. This agrees with the results of Germer (2010), Alaoui et al. (2011), Jost et al. (2012), Scherrer et al. (2007), which indicated that infiltration-excess is negligible in forested soils.

At the start of the autumnal rainy season, in the grassed site soil cracks and some micro fauna burrows present in the soil surface allowed the intense rainfall to entirely infiltrate into the soil. Due to the medium soil depth, the empty soil porosity, and the still high soil water evaporation in this period, the rainfall did not saturate the soil completely. This prevented substantial runoff generation in this period. This was evident during site surveys, but was also confirmed by the analysis of Niedda and Pirastru (2014), which found that the runoff coefficient computed at the Baratz catchment outlet was always less than $2 \%$ during the autumn. Their continuous simulation model, which ignores the infiltration-excess mechanism (Niedda, 2004; Niedda and Pirastru, 2013; Niedda and Pirastru, 2014) for runoff generation, effectively simulated the stream discharge in this catchment in the years 2009-2013. In the winter the expansion of the soil aggregates caused the surface cracks to close, and this reduced the permeability of the soil. However, on only one occasion did the 5 min rainfall intensities exceed the mean $K_{f s}$ measured in the topsoil in winter. Hence we conclude that even in the winter periods the infiltration-excess was negligible in the grassed site.

Characterising the soil drainage mechanisms is crucial when attempting to identify how a hillslope responds to precipitation. On one hand, the subsurface flow is itself a source of significant runoff during stormflow, and on the other it substantially controls the frequency of soil saturation, by controlling the water storage capacity prior to the rain events. In the maquis site, unlike in the grassy site, the high volume of soil macropores guaranteed efficient vertical soil drainage during the infiltration tests and during natural rainfall events. Because deep percolation is prevented by the low-permeable substratum, the rapid lowering of the water table after the rain events suggests that the pore network in the maquis soil was also efficient in transmitting the subsurface flow down the slope. The living and decaying roots of the maquis also helped to improve the efficiency of subsurface flow in this soil. Observations in situ of the distribution of tree and bush roots indicated that the fine roots are abundant in the surface layers, and that many coarse roots develop in the deeper soil, spreading both laterally and vertically. This root structure contributes to creating a continuous and well interconnected network of biopores and pipes along the hillslope. The importance of tree roots in determining the water flow dynamics of the soil was highlighted by Jost $e t$ al. (2012). They showed how different root structures resulted in different soil moisture levels and runoff processes. In the maquis site the subsurface flow lowered the water table considerably, both prior to and during rain events, so that a great deal of water was needed to raise the water content until the entire soil profile was saturated. The canopy interception and the water retained by the thick litter on the soil surface created additional water storage, and also contributed to delaying the beginning of the perched water table. Hence the efficient drainage and high interception, in association with the high porosity of the natural soil, prevented the entire profile becoming saturated even in the times of the heaviest rainfall.

In the grassed site the persistence, for long periods, of high mois- 
ture levels and the perched water table indicates that there was water logging. This was due to the alteration in the soil structure caused by the land use change, which reduced the volume and continuity of the macropores. This is in line with the findings of Alaloui et al. (2011), who observed that, when compared to forested soils, macropores and biopores in grassland are less efficient in draining water. As a result, in the grassed site even small amounts of rainfall were enough to completely saturate the soil during the rain events. Because of the proximity of the water table to the soil surface in the wet periods, saturated areas spread quickly over the whole hillside during rain events. This is in agreement with the variable source areas (VSA) concept of Hewlett and Hibbert (1967). There were many similarities in the findings of McDaniel et al. (2008). They studied soil moisture and perched water table dynamics in a grassed catchment area with a shallow fragipan. They ascribed the formation of VSA in the catchment area to the spatial patterns of the impeding layer. In the area we studied, low-permeable sandstone is evenly present at the same depth in both the maquis and grassed sites. However, saturation of the entire soil profile only occurred in the grassed area, which indicates that the type of land use, rather than the presence of the shallow impeding layer, was primarily responsible for controlling this process.

\section{Conclusions}

This work compares the hydrological properties and the hydrological dynamics of a soil covered with Mediterranean maquis and an adjacent soil covered with spontaneous grass. The results of this investigation refer to the specific situation of the research site. The grassed plot was cleared of maquis 10 years ago and deep ploughed, and then unmanaged spontaneous grass grew on it. However, our results may provide some indications, in other similar Mediterranean environments, of the changes which may occur in the hydraulic properties of the soil and in its hydrological processes when the natural vegetation is cleared.

In the grassed site, compared to the maquis site, there was a less amount of organic matter and the bulk density was increased. Soil compaction was ascribed to the decrease in the volume of the pores that are activated in the water tension range from $-50 \mathrm{~cm}$ to soil water saturation. The seasonal susceptibility of the grassy soil to shrinking increased the vertical saturated hydraulic conductivity during the dry summer. Because these cracks conducted water downward in a similar way to the macropores of the maquis soil, measuring the saturated soil conductivity in dry soil conditions did not show completely the influences of the different land uses on the hydraulic properties of the soil. During the wet winter period the closing of the cracks decreased soil conductivity in the grassy soil, while the opposite happened to the soil under the maquis. As result, the effects of the land uses on the hydraulic conductivity of the soil were mainly evident in the wet season. Because seasonal changes in the soil structure may also substantially alter the hydraulic behaviour of the soil, the seasonal dynamics of the hydrological properties of the soil should be taken into account in the hydrological analysis. Ignoring these influences may result in misleading results being obtained by field surveys of hydraulic conductivity, as well in the models for simulating the hydrological processes of the soil. The dynamics of soil moisture and the perched water table were different with different land uses. High soil moisture and a high water table persisted throughout the wet season in the grassed site. In the maquis site only short-lived, event based, perched water tables were observed. These differences were due to the high level of rain interception by maquis canopy, and the changes in infiltration, subsurface drainage and the water storage processes in the grassy soil. Characterisation of the hydraulic properties of the soil allowed us to hypothesise on the possible causes of these changes. The conductivity and retention data collected in the maquis site suggested that macropores are abundant in this soil, and govern the fast subsurface flow through it. The high organic matter content of this soil also ensured that the system remained stable over time. In the grassy area the laboratory and field data indicated that the macropores were destroyed. This resulted in inefficient soil drainage and the soil being saturated during rainy periods. Further research should be directed at characterising the hydrological response of soils at the hillslope-scale and during extreme precipitation, which is frequent in the Mediterranean environment. Creating an experimental template that includes artificial intense rainfall equipment, surface runoff and subsurface flow measurers might be useful for obtaining information about both hillslopescale hydraulic conductivity and the hydrological response of the soils to extreme events. We intend to do this in future research.

\section{References}

Agnese C., Bagarello V., Baiamonte G., Iovino M. 2011. Comparing physical quality of forest and pasture soils in a Sicilian watershed. Soil Sci. Soc. Am. J. 75:1958-70.

Alaoui A., Caduff U., Gerke H.H., Weingartner R. 2011. Preferential flow effects on infiltration and runoff in grassland and forest soils. Vadose Zone J. 10:367-77.

Angulo-Jaramillo R., Vandervaere J.P., Roulier S., Thony J.L., Gaudet J.P., Vauclin M. 2000. Field measurement of soil surface hydraulic properties by disc and ring infiltrometers: a review and recent developments. Soil Till. Res. 55:1-29.

Arya L.A. 2002. Wind and hot-air methods. In: J.H. Dane and G.C. Topp (eds.), Methods of soil analysis, Part 4: Physical methods. Soil Science Society of America, Madison, WI, USA, pp 916-926.

Bagarello V., Baiamonte G., Castellini M., Di Prima S., Iovino M. 2014. A comparison between the single ring pressure infiltrometer and simplified falling head techniques. Hydrol. Process. 28:4843-53.

Bagarello V., Castellini M., Iovino M. 2005. Influence of the pressure head sequence on the soil hydraulic conductivity determined with tension infiltrometer. Appl. Eng. Agric. 21:383-91.

Bagarello V., Castellini M., Iovino M., Sgroi A. 2010. Testing the concentric-disk tension infiltrometer for field measurement of soil hydraulic conductivity. Geoderma 158:427-35.

Bormann H., Klaassen K. 2008. Seasonal and land use dependent variability of soil hydraulic and soil hydrological properties of two German soils. Geoderma 145:295-302.

Buczko U., Bens 0., Hüttl R. F. 2006. Water infiltration and hydrophobicity in forest soils of a pine-beech transformation chronosequence. J. Hydrol. 331:383-95.

Cantón Y., Solé-Benet A., De Vente J., Boix-Fayos C., Calvo-Cases A., Asensio C., Puigdefábregas J. 2011. A review of runoff generation and soil erosion across scales in semiarid south-eastern Spain. J. Arid Environ. 75:1254-61.

Castellini M., Niedda M., Pirastru M., Ventrella, D. 2014. Temporal changes of soil physical quality under two residue management systems. Soil Use Manage. 30:423-34.

Castellini M., Ventrella D. 2012. Impact of conventional and minimum tillage on soil hydraulic conductivity in typical cropping system in Southern Italy. Soil Till. Res. 124:47-56.

Celik I. 2005. Land-use effects on organic matter and physical properties of soil in a southern Mediterranean highland of Turkey. Soil Till. Res. 83:270-7. 
Costa M.H., Botta A., Cardille J.A. 2003. Effects of large-scale changes in land cover on the discharge of the Tocantins Rivers, Southeastern Amazonia. J. Hydrol. 283:206-17.

Daraghmeh 0.A., Jensen J.R., Petersen C.T. 2008. Near-saturated hydraulic properties in the surface layer of a sandy loam soil under conventional and reduced tillage. Soil Sci. Soc. Am. J. 72:1728-37.

Das Gupta S., Mohanty B.P., Köhne J.M. 2006. Soil hydraulic conductivities and their spatial and temporal variations in a vertisol. Soil Sci. Soc. Am. J. 70:1872-881.

De Moraes J.M., Schuler A.E., Dunne T., Figueiredo R.D.0., Victoria R.L. 2006. Water storage and runoff processes in plinthic soils under forest and pasture in Eastern Amazonia. Hydrol. Process. 20:2509-26.

Dekker L.W., Ritsema C.J. 2000. Wetting patterns and moisture variability in water repellent Dutch soils. J. Hydrol. 231:148-64.

Elrick D.E., Reynolds W.D. 1992. Methods for analyzing constant-head well permeameter data. Soil Sci. Soc. Am. J. 56:320-3.

Etana A., Larsbo M., Keller T., Arvidsson J., Schjønning P., Forkman J., Jarvis N. 2013. Persistent subsoil compaction and its effects on preferential flow patterns in a loamy till soil. Geoderma 192:4306.

Evrendilek F., Celik I., Kilic S. 2004. Changes in soil organic carbon and other physical soil properties along adjacent Mediterranean forest, grassland, and cropland ecosystems in Turkey. J. Arid Environ. 59:743-52.

Fu B., Wang J., Chen L., Qiu Y. 2003. The effects of land use on soil moisture variation in the Danangou catchment of the Loess Plateau, China. Catena 54:197-213.

Gajić B. 2013. Physical properties and organic matter of Fluvisols under forest, grassland, and 100 years of conventional tillage. Geoderma 200-201:114-9.

Gallart F., Latron J., Llorens P., Rabadà D. 1997. Hydrological functioning of Mediterranean mountain basins in Vallcebre, Catalonia: some challenges for hydrological modelling. Hydrol. Process. 11:1263-72.

Germer S., Neill C., Krusche A.V., Elsenbeer H. 2010. Influence of land-use change on near-surface hydrological processes: undisturbed forest to pasture. J. Hydrol. 380:473-80.

Gonzalez-Sosa E., Braud I., Dehotin J., Lassabatère L., AnguloJaramillo R., Lagouy M., Branger F.C., Jacqueminet Kermadi S., Michel K. 2010. Impact of land use on the hydraulic properties of the topsoil in a small French catchment. Hydrol. Process. 24:238299.

Hassler S.K., Zimmermann B., van Breugel M., Hall J.S., Elsenbeer H. 2010. Recovery of saturated hydraulic conductivity under secondary succession on former pasture in the humid tropics. Forest Ecol. Manag. 261:1634-42.

Hewlett J.D., Hibbert A.R. 1967. Factors affecting the response of small watershed to precipitation in humid areas. In: W.E. Sopper and H.W. Lull. (eds.), International Symposium of Forest Hydrology, Pergamon Press, Oxford, UK, pp 275-290.

Hu W., Shao M.A., Si B.C. 2012. Seasonal changes in surface bulk density and saturated hydraulic conductivity of natural landscapes. Eur. J. Soil Sci. 63:820-30.

Iovino M., Castellini M., Bagarello V., Giordano G. 2013. Using static and dynamic indicators to evaluate soil physical quality in a Sicilian area. Land Degrad. Dev. [In press].

Jost G., Schume H., Hager H., Markart G., Kohl B. 2012. A hillslope scale comparison of tree species influence on soil moisture dynamics and runoff processes during intense rainfall. J. Hydrol. 420:112-24.

Lee D.M., Elrick D., Reynolds W., Clothier B.E. 1985. A comparison of three field methods for measuring saturated hydraulic conductivity. Can. J. Soil Sci. 65:563-73.

Llorens P., Domingo F. 2007. Rainfall partitioning by vegetation under Mediterranean conditions. A review of studies in Europe. J. Hydrol. 335:37-54.

Martinez L.J., Zink J.A. 2004. Temporal variation of soil compaction and deterioration of soil quality in pasture areas of Columbian Amazonia. Soil Till. Res. 75:3-18.

McDaniel P.A., Regan M.P., Brooks E., Boll J., Barndt S., Falen A., Young S.K., Hammel J.E. 2008. Linking fragipans, perched water tables, and catchment-scale hydrological processes. Catena 73:166-73.

Messing I., Jarvis N.J. 1993. Temporal variation in the hydraulic conductivity of a tilled clay soil as measured by tension infiltrometers. J. Soil Sci. 44:11-24.

Mollnau C., Newton M., Stringham T. 2014. Soil water dynamics and water use in a western juniper (Juniperus occidentalis) woodland. J. Arid Environ. 102:117-26.

Niedda M. 2004. Upscaling hydraulic conductivity by means of entropy of terrain curvature representation. Water Resour. Res. 40:W04206.

Niedda M., Pirastru M. 2013. Hydrological processes of a closed catchment-lake system in a semi-arid Mediterranean environment. Hydrol. Process. 27:3617-26.

Niedda M., Pirastru M. 2014. Field investigation and modelling of coupled stream discharge and shallow water-table dynamics in a small Mediterranean catchment (Sardinia). Hydrol. Process. 28:5423-35.

Niedda M., Pirastru M., Castellini M., Giadrossich F. 2014. Simulating the hydrological response of a closed catchment-lake system to recent climate and land-use changes in semi-arid Mediterranean environment. J. Hydrol. 517:732-45.

Nimmo J.R. 2012. Preferential flow occurs in unsaturated conditions. Hydrol. Process. 26:786-9.

Piňol J., Beven K., Freer J. 1997. Modelling the hydrological response of Mediterranean catchments, Prades, Catalonia. The use of distributed models as aids to hypothesis formulation. Hydrol. Process. 11:1287-306.

Pirastru M., Niedda M. 2010. Field monitoring and dual permeability modelling of water flow through unsaturated calcareous rocks. J. Hydrol. 392:40-53.

Pirastru M., Niedda M. 2013. Evaluation of the soil water balance in an alluvial floodplain with a shallow groundwater table. Hydrolog. Sci. J. 58:898-912.

Price K., Jackson C.R., Parker A.J. 2010. Variation of surficial soil hydraulic properties across land uses in the southern Blue Ridge Mountains, North Carolina, USA. J. Hydrol. 383:256-68.

Reynolds W.D., Elrick D.E. 1991. Determination of hydraulic conductivity using a tension infiltrometer. Soil Sci. Soc. Am. J. 55:633-9.

Reynolds W.D., Elrick D.E. 2002. Pressure infiltrometer. In: J.H. Dane and G.C. Topp (eds.), Methods of soil analysis, Part 4: Physical methods. Soil Science Society of America, Madison, WI, USA, pp 826-836.

Reynolds W.D., Elrick D.E., Youngs E.G. 2002. Ring or cylinder infiltrometers (vadose zone). In: J.H. Dane and G.C. Topp (eds.), Methods of soil analysis, Part 4: Physical methods. Soil Science Society of America, Madison, WI, USA, pp 818-820.

Rockefeller S.L., McDaniel P.A., Falen A.L. 2004. Perched water table responses to forest clearing in northern Idaho. Soil Sci. Soc. Am. J. 68:168-74.

Rotondi A., Rossi F., Asunis C., Cesaraccio C. 2003. Leaf xeromorphic adaptations of some plants of a coastal Mediterranean macchia ecosystem. J. Mediterr. Ecol. 4:25-36. 
Sauer T.J., Logsdon S.D. 2002. Hydraulic and physical properties of stony soils in a small watershed. Soil Sci. Soc. Am. J. 66:1947-56.

Scherrer S., Naef F., Faeh A.0., Cordery I. 2007. Formation of runoff at the hillslope scale during intense precipitation. Hydrol. Earth Syst. Sc. Discuss. 11:907-22.

Schume H., Jost G., Hager H. 2004. Soil water depletion and recharge patterns in mixed and pure forest stands of European beech and Norway spruce. J. Hydrol. 289:258-74.

Schwartz R.C., Evett S.R., Unger P.W. 2003. Soil hydraulic properties of cropland compared with reestablished and native grassland. Geoderma 116:47-60.

Sleutel S., De Neve S., Singier B., Hofman G. 2007. Quantification of organic carbon in soils: a comparison of methodologies and assessment of the carbon content of organic matter. Commun. Soil Sci. Plan. 38:2647-57.

Spano D., Snyder R.L., Sirca C., Duce P. 2009. ECOWAT - A model for ecosystem evapotranspiration estimation. Agr. Forest. Meteor. 149:1584-96.

van Genuchten M.Th. 1980. A closed form equation for predicting the hydraulic conductivity of unsaturated soil. Soil Sci. Soc. Am. J.
44:892-8.

van Genuchten M.Th., Leij F.J., Yates S.R. 1991. The RETC code for quantifying the hydraulic functions of unsaturated soils, Version 1.0. Riverside, CA. US Environmental Protection Agency, EPA Report 600/2-91/065.

van Genuchten MTh., Nielsen D.R. 1985. On describing and predicting the hydraulic properties of unsaturated soils. Ann. Geophys. 3:615-28.

Warrick A.W. 1998. Spatial variability. In: Hillel D (ed.), Environmental soil physics. Academic Press, San Diego, CA, USA, pp 655-675.

Wooding R.A. 1968. Steady infiltration from a shallow circular pond. Water Resour. Res. 4:1259-73.

Zhou X., Lin H.S., White E.A. 2008. Surface soil hydraulic properties in four soil series under different land uses and their temporal changes. Catena 73:180-8.

Zimmermann B., Elsenbeer H., De Moraes J.M. 2006. The influence of land-use changes on soil hydraulic properties: Implications for runoff generation. Forest Ecol. Manage. 222:29-38. 